Session 1165

\title{
Mini-Term Abroad Programs in Brasil and Scotland for Engineering, Science, and Liberal Arts Majors
}

\author{
Karen Williams, Associate Research Professor of Biological Sciences, \\ George Williams, Professor of Electrical Engineering and Computer Science, \\ Phillip Snow, Associate Professor of Civil Engineering
}

Union College, 807 Union Ave., Schenectady, NY 12308

\begin{abstract}
Both the General Education Program and the new Engineering curriculum for undergraduates at Union College require of students either three courses in a foreign culture or an international experience. To provide this experience, we initiated a miniterms abroad program. This paper describes two mini-term courses which are compatible with existing engineering course schedules and emphasize a theme that is part of the new engineering curriculum at Union - multi-disciplinary solutions to complex problems.
\end{abstract}

The first Union mini-term abroad to be established was a three-week visit to Sao Paulo, Brasil, to study the effects of water resources and water pollution on a large urban city. The Brasilian program, which has been offered during the last five years starting in the winter term break of 1997, is coordinated by two Union faculty members - a civil engineer and a sociologist. It was developed especially for engineers with an emphasis on hydroelectric power, water and wastewater treatment, river and reservoir watersheds along with social, political, and economic interactions. Based on this offering, another mini-term in urban Scotland has been developed and was offered for the first time in the summer of 2001. Based in Glasgow, it is coordinated by two Union faculty members - a computer scientist and a biologist. Presentation topics in Scotland include bioinformatics, novel pharmaceutical delivery systems, public health data analysis, proteomics, and cloning.

The mini-term format achieves several objectives: it is a course that is scheduled over two terms and the intervening break so that it can be taken in parallel with regular co urse schedules; it uses multi-disciplinary student teams to study how technology can improve quality of life; and it encourages information gathering by critical listening, first-hand observation, and directed library research culminating in both oral and written presentations. 
The Christian A. Johnson Endeavor Foundation has funded the development of mini-term programs at Union College. Funding was also provided by the Keck Foundation. Positive assessment results and prospective student requests have encouraged expanded offerings of the mini-term abroad courses.

\section{Introduction}

Union College is a small liberal arts and engineering school with 2000 undergraduate students. In the 1999-2000 school year, 336 (17\%) students participated in a term abroad experience. Prior to graduation, $60-65 \%$ of all students participate in some form of a foreign experience.

The General Education Program and the new Engineering curriculum for undergraduates at Union College both require an international experience of students. To provide this experience, we initiated a pilot mini-term abroad in Brasil in December 1997. This program has been offered each year since and is the model for other mini-terms such as the one in Scotland, which was initiated in August 2001. This paper describes both of these mini-term courses which are compatible with existing engineering course schedules and emphasize a theme that is part of the new engineering curriculum at Union - multidisciplinary solutions to complex problems. In addition, both mini-term courses broaden the students' understanding of the impact of engineering solutions in a global and societal context.

\section{Mini-Term in Brasil}

The mini-term in Sao Paulo, Brasil, the first mini-term offered at Union College, was originally created as a pilot program with an innovative, interdisciplinary approach to international education for teams of liberal arts and engineering students. The course ${ }^{3}$ was first offered in December 1997 with 12 students. It features a three and one half week travel format for multi-disciplinary student groups. ${ }^{2}$ It is organized by two faculty members - one from the Civil Engineering Department, and one from the Sociology Department.

\section{A. Goals and Objectives}

The current course provides an intensive exposure to the engineering and social science issues (water-related problems) in three different cities in Brasil. This usually involves 12 to15 different field trips, 5 to 8 guest lecturers, and $2000 \mathrm{~km}$ of travel in the state of Sao Paulo. Student teams investigate the multi-disciplinary problems and describe the solutions that have been implemented or will be implemented. The students attend all of the lectures and field trips to develop an understanding of the technical, as well as the social, political, and economic, ramifications of every topic.

\section{B. Why Brasil?}


Brasil offers a rich variety of student research topics: drinking water distribution systems; domestic wastewater collection and treatment; industrial and domestic solid waste disposal; watersheds and river pollution control; hydroelectric power generation; and reservoirs and their watersheds. For example, the Tiete River in Sao Paulo, which receives raw wastewater from 10 million people, is one of the most polluted rivers in the world. Each of these topics includes a multi-disciplinary mix of technological, scientific, social, political, and economic issues. Typical sites visited by students are Guarau, the largest drinking water treatment plant in South America, and Cubatao, the large petrochemical/industrial complex and hydroelectric generator station near Sao Paulo with its various air and water pollution problems.

\section{Who might go?}

Junior and Senior students who are engineering, science, or liberal arts majors are recruited and interviewed. The audience is limited to about 12 students who work in groups, with liberal arts majors helping engineering majors to assess the political, cultural, economic, and ethical facets of the problems; and engineering majors helping the liberal arts majors to assess the engineering and scientific facets of the problems.

\section{Timeline}

The mini-term course is organized so that the travel to Brasil begins in late November while Union is on break so students do not miss any required classes. The program has three parts: (1) a pre-seminar in the Fall term for introducing the Portuguese language and providing background material on the culture and history of Brasil, (2) a three and onehalf week visit to three Brasilian cities: Sao Paulo, Sao Carlos, and Rio; and (3) a follow up seminar in the Winter term for writing and orally presenting a research paper. Each team is expected to present their paper to the college community at the Union College Steinmetz Symposium in the following Spring term.

\section{E. Brasil Mini-Term Calendar}

The activities for the students include unscheduled time so that they can explore parts of Brasil on their own. The language barrier made this a challenge until the students learned some Portuguese. The complete three week calendar is available on the WWW at http://tardis.union.edu/ williamg/Brasil/calendar_2000.html .

\section{F. Evaluation of Student Work}

The student's work is evaluated by examination of his/her journal, notes from Union College speakers, notes from resident experts in Brasil, an annotated bibliography to summarize the library research, a term paper (and its first draft), seminar presentations, and the organization of all the material into a PowerPoint oral presentation. 


\section{G. Program Assessment}

The students complete the standard college course evaluation form and a 6-page form based specifically on the mini-term experience. In general they found the course to be very challenging. The language and the technical terms were a hurdle, but the instructors were careful to explain terms that the speakers and the translator missed. Students praised the homestay plan (living with a family in Sao Paulo), and all of them have enjoyed the wide variety of speakers and trips and the opportunity to meet Brasilians. The program has been popular and has been fully subscribed every year. Students' final term papers and presentations document their increased awareness about the impact of engineering solutions in a global and societal context.

\section{Mini-Term in Scotland}

The mini-term in Scotland, which, like the mini-term in Brasil, offers an innovative, interdisciplinary approach to international education, features a three-week travel format for multi-disciplinary student groups. ${ }^{2}$ The course,${ }^{4}$ based in Glasgow, was first offered in August 2001 with 12 students. It was organized by two faculty members - one from the Electrical Engineering and Computer Science Department, and one from the Biology Department.

\section{A. Goals and Objectives}

Like the Brasilian mini-term, the mini-term abroad in Scotland, which is based in Glasgow, emphasizes a theme that is part of the new engineering curriculum - multi-disciplinary solutions to complex problems - converging technology More specifically, it focuses on health problems confronting the Scottish people and the extent to which biotechnology is being used to address those problems.

\section{B. Why Scotland?}

Scotland is a country that is noteworthy for its proud cultural heritage, an impressive record of innovation and invention, and strong educational/medical institutions which can produce economic growth based on advanced medical research and high technology computer development. ${ }^{1}$ Nevertheless, the Scottish people, especially those in the lower socioeconomic groups, are faced with significant challenges to their health, among them: alcoholism, smoking, and poor diet. In fact, Glasgow has the dubious distinction of being known as "The Cancer Capital of the World." In Scotland, students hear presentations by 15-20 health care professionals, scientists, and academics at both universities and research facilities. Each venue provides a different perspective on the general theme: "How can diverse institutions, that are devoted to computer technology and medical research, interact and complement each other to improve the health of the Scottish people?" For example, students learn about bioinformatics, nanotechnology, public health, and dental health at the University of Glasgow; novel pharmaceutical delivery 
systems, remote monitoring of patient status, and tobacco control at the University of Strathclyde; proteomics, early cancer detection, and confocal microscopy at the Beatson laboratories; and cloning at the Roslin Institute (home of Dolly the sheep).

\section{Who might go?}

Rising Junior and Senior students who are engineering, natural science, or liberal arts majors are recruited and interviewed. The audience is limited to 12 students who are organized into multidisciplinary teams of two to three members each. The mini-term offers a rich combination of experiences which make it attractive to students in all of these areas--computer technology for engineering majors, medical research for natural science majors, and culture/history for liberal arts majors.

\section{Timeline}

The mini-term course is organized so that the travel to Scotland occurs in August while Union is on break so students do not miss any required classes. The program has three parts: (1) a pre-seminar in the Spring term which includes background material on Scotland and guest lecturers from the departments of English, History, Philosophy, and Performing Arts, (2) a three week visit to three Scottish cities: Glasgow, Edinburgh, and St. Andrews; and (3) a follow up seminar in the Fall term for writing and presenting a research paper.

During the Scotland visit, students document their experiences in a daily journal and gain additional insight from visits to museums, arts festivals, and other cultural events; personal contact with people at local community centers; and organized city tours led by local guides. The follow up seminar is devoted to discussing and writing a paper that is presented at the end of the program. Each team is encouraged to present their paper to the college community at the Union College Steinmetz Symposium in the following Spring term.

\section{E. Scotland Mini-Term Calendar}

The calendar of events is handed out to the students at the beginning of the visit to Scotland. The advisors also suggested a list of places to visit during the unscheduled times on the calendar. Students formed groups and traveled on their own by train or bus to many different destinations including Oban, Inverness, Stirling, and the Isle of Skye. The complete three week calendar is available on the WWW at http://tardis.union.edu/ williamg/Scotland/calendar_2001.html

\section{F. Evaluation of Student Work}

The student's work is evaluated by examination of his/her journal, notes from Union college speakers, notes from resident experts in Scotland, an annotated bibliography to summarize the library research, a term paper (and its first draft), seminar presentations, and the organization of all the material into a course portfolio. A first draft of the paper is 
reviewed by both peers and faculty. In addition, the faculty who attended all presentations and events, gave the students a pop quiz during the train trip to St. Andrews.

\section{G. Program Assessment}

The students complete standard course evaluation form as well as a mini-term evaluation form to assess the experience. While this course presented a significant academic challenge particularly to Engineering/CS majors with little background in biology, and other majors with little background in Engineering and Computer Science, the comments about the mini-term experience were very positive. Students from all majors particularly enjoyed the mix of activities. Their final term papers documented their increased awareness about the impact of engineering solutions in a global and societal context.

\section{Funding}

Funding for the Brasil mini-term is provided by a grant from the Christian A. Johnson Endeavor Foundation and the Keck Foundation. The Scotland mini-term is funded by Keck Foundation.

\section{Conclusions}

The mini-term format achieves several objectives: it is a course that is scheduled over two terms and the intervening break so that it can be taken in parallel with regular course schedules; it uses multidisciplinary student teams to study how technology can improve quality of life; and it encourages information gathering by critical listening, first-hand observation, and directed library research.

Positive assessment results and prospective student requests have encouraged expanded offerings of the mini-term abroad courses.

\section{References}

1. Devine, T. M., The Scottish Nation, a history 1700-2000, Viking Penguin Press, 1999, ISBN 0-67088811-7.

2. "Engineering, Technology, and Society: Increasing the Dialogue Between Liberal Arts Majors and Engineering Students", Joan Burtner, Mercer University, presented at 2001 ASEE Annual Conference, Albuquerque, New Mexico, June 2001.

3. Snow, Phillip, "Union College Mini-term Course in Brasil", Dec 2000, retrieved from the WWW on Jan 2002, http://www.union.edu/PUBLIC/CERDEPT/Brasil/Brasil00.htm .

4. Williams, George, "Union College Mini-term in Scotland, Dec 2000, retrieved from the WWW on Jan 2002, http://tardis.union.edu/ williamg/Scotland/ . 
KAREN N. WILLIAMS, PhD, Associate Research Professor of Biological Sciences, Union College, Schenectady, NY 12308; williamk@union.edu .Williams has taught courses in introductory biology, comparative anatomy, and human genetics since 1972.

GEORGE H. WILLIAMS, PhD, Professor of Electrical Engineering and Computer Science, Union College, Schenectady, NY 12308; williamg@tardis.union.edu . Williams has taught courses in software design and algorithms since 1970.

PHILLIP D. SNOW, PhD, Associate Professor of Civil Engineering, Union College, Schenectady, NY 12308; snowp@union.edu . Snow has taught courses in civil engineering, water resources, and environmental sciences since 1974. 